\title{
KEGELISAHAN DOSA DALAM PERSPEKTIF HADIS
}

\author{
A. DARUSSALAM \\ Universitas Islam Negeri Alauddin Makassar \\ Sulawesi Selatan, Indonesia \\ Email: andidarus59@gmail.com
}

\section{Abstrak}

Anxiety is a psychological disorder that has begun to get the attention of scholars in the field of psychology. Existing theories and conceptual frameworks about anxiety primarily refer to western scholars. However, theories and conceptual frameworks proposed by Western scholars are not suitable for use as point of reference in the life of a Muslim. Thus, the purpose of this article is to analyze the concept of anxiety specifically caused by sin based on the perspective of the hadith using content analysis methods by identifying the hadiths and opinions of relevant and related scholars. This study found that good deeds (something that is rewarded), will lead to the peace of the soul, due to the grace that is poured on him. Vice versa, if someone commits evil (sin), then the calmness of his soul will be disturbed, leading to anxiety, because of denying his instinctive nature (fitrah).

\section{Keywords}

Hadis, Psikologi, Islam, Dosa

\section{Pendahuluan}

Manusia merupakan makhluk yang selain memiliki fisik, pancaindra, dan akal pikiran, juga memiliki fitrah, hati nurani, dan spiritualitas. Keadaan fisik, pancaindra, dan akal pada hakikatnya merupakan kendaraan yang mengikuti keinginan hati nurani dan spiritual. Jika keadaan hati nurani dan spiritualnya positif, maka sesuatu yang akan dilakukan oleh 
fisik dan pancaindra, serta yang dikeluarkan oleh akal pikiran juga positif dan demikian seterusnya. ${ }^{1}$

Namun demikian, manusia lahir di dunia dilengkapi oleh segala kelebihan dan kekurangan. Tidak dipungkiri, manusia hadir dan tercipta sebagai individu yang unik, masing-masing membawa corak yang berbeda dalam berinteraksi dengan lingkungannya. Pengaruh lingkungan erat kaitannya dengan moral setiap individu. Namun moral juga memiliki hubungan yang erat dengan keyakinan. ${ }^{2}$

Keyakinan yang dimaksud ialah berupa keyakinan dalam menganut agama. Manusia dilengkapi dengan kecerdasan, namun tidak ada artinya jika tidak diseimbangkan dengan agama. ${ }^{3}$ Hal ini disebabkan agama adalah suatu wadah untuk membawa kepada ketenangan jiwa dan batin seseorang. Dosa-dosa yang disebabkan karena melanggar norma agama akan membawa kepada kegelisahan. Berdasarkan penjelasan pada latar belakang di atas, penulis mencoba menggali ontologi dari dosa; bagaimana penjelasan Islam (teks hadis) yang terkait tentang dosa membuat jiwa gelisah. Penulis menggunakan pendekatan kualitatif dengan menggunakan analisis konten (content analysis), dengan cara mencari hadis-hadis yang berkaitan dengan "kegelisahan karena dosa" dari kitab hadis Kutub al-Sittah dan mengumpulkan argumen yang terkait dengan tema bahasan sehingga dapat melahirkan kesimpulan yang komprehensif.

${ }^{1}$ Abuddin Nata, Psikologi Pendidikan Islam (Cet. I; Depok: Rajagrafindo Persada, 2018), h. 1.

2Yudrik Jahja, Psikologi Perkembangan (Cet. II; Jakarta: Kencana, 2012), h. 404.

${ }^{3}$ Yudrik Jahja, Psikologi Perkembangan, h. 404.

TAHDIS Volume 10 Nomor 2 Tahun 2019 


\section{Ilmu Jiwa (Psikologi) dan Studi Islam}

Manusia adalah makhluk ciptaan Allah swt. yang paling sempurna dibanding dengan makhluk yang lainnya, karena telah diberi akal pikiran. Sejak tumbuh dan timbulnya kesadaran dalam diri manusia, ia telah merenungkan tentang arti hidup dan keberadaan hidup di dunia.

Dalam kehidupan sehari-hari, banyak hal yang ditemukan terkait istilah yang sering menggambarkan sikap jiwa seseorang. Dalam studi agama, teori psikologi digunakan untuk menjelaskan gejala-gejala lahiriah orang beragama, di mana hubungan antara perilaku dan yang tampak dengan keyakinan keagamaan seseorang muslim. Misalnya sikap bersedekah kepada fakir miskin, beriman serta bertakwa kepada Allah swt., sikap tolong-menolong sesama individu dengan individu atau individu dengan masyarakat dan sikap hormat-menghormati sesama muslim. Semua gejala tersebut termasuk dalam kejiwaan yang berhubungan dengan agama. ${ }^{4}$ Dengan adanya gejala tersebut, maka psikologi Islami merupakan salah-satu solusi untuk mengetahui ihwal yang terjadi pada diri atau kejiwaan seseorang yang berhubungan dengan agama.

Psikologi Islam merupakan studi Islam yang terkait perilaku jiwa manusia, sehingga ia dapat secara sadar membentuk kualitas (diri) yang lebih baik dan memperoleh kebahagiaan dunia dan akhirat. Sifat definisi tersebut mengandung tiga elemen utama: Pertama, psikologi Islam adalah salah satu studi kajian ke-Islaman. Psikologi Islam memiliki posisi yang serupa dengan disiplin ilmu Islam lainnya, seperti ekonomi Islam, politik Islam, sosiologi Islam, dan lain sebagainya. Penggunaan kata "Islam" memiliki gaya, perspektif,

${ }^{4}$ Novita Rahmi, "Manusia dalam Perspektif Psikologi Pendidikan Islam", Dewantara 11. (2016): h. 207. 
pola pikir, paradigma atau aliran tersendiri. Artinya, psikologi dibangun berpola atau memiliki pola pikir yang berlaku pada tradisi ilmiah dalam Islam, sehingga dapat membentuk alirannya sendiri yang berbeda dengan psikologi pada umumnya (konvensional). Tentu hal tersebut tidak terlepas dari sifat jiwa itu sendiri, cara mempelajari jiwa dan tujuan mempelajari jiwa dalam Islam. Melalui kerangka kerja ini, ia akan menciptakan beberapa bagian psikologi dalam Islam, seperti psikologi agama Islam, psikologi perkembangan Islam, psikologi sosial Islam dan sebagainya. ${ }^{5}$

Kedua, Psikologi Islam membahas aspek dan perilaku kejiwaan manusia. Aspek kejiwaan dalam Islam dalam bentuk al-Ruh, al-Qalb, al-Aql dan al-Fitrah. Masing-masing aspek ini memiliki keberadaan, kedinamisan, proses, fungsi dan perilaku yang perlu didalami melalui Alquran, al-sunah serta dari khazanah pemikiran Islam. Psikologi Islam tidak hanya menekankan perilaku kejiwaan, tetapi juga apa hakikat jiwa yang sebenarnya. Sebagai sebuah organisasi permanen, jiwa manusia adalah potensi aktualisasi dalam perilaku yang sangat tergantung pada upayanya (ikhtiar). Dari sini nampak bahwa ilmu psikologi Islam mengakui keberadaan kesadaran serta kebebasan manusia agar menciptakan, berpikir, berniat dan berperilaku secara sadar, meskipun kebebasan tetap berada di koridor sunah Allah. ${ }^{6}$

Ketiga, psikologi Islam mempunyai tujuan, yakni merangsang kesadaran (diri) untuk dapat membentuk kualitas yang lebih sempurna dari sebelumnya, mendapatkan kebahagiaan hidup, baik di dunia dan akhirat. Manusia saat dilahirkan dalam kondisi tidak mengetahui apa-apa, lalu

5Fitriana, "Pengertian, Dasar dan Ruang Lingkup Psikologi Islam", diakses pada: 21-September-2019, 23:03

6 Fitriana, "Pengertian, Dasar dan Ruang Lingkup Psikologi Islam"

TAHDIS Volume 10 Nomor 2 Tahun 2019 
tumbuh dan berkembang untuk mencapai kualitas hidup yang lebih baik dari sebelumnya. Psikologi Islam adalah salah satu disiplin ilmu yang dapat membantu dalam memahami ekspresi diri, aktualisasi diri, konsep diri, citra diri, realisasi diri, kesadaran diri, harga diri, kontrol diri dan evaluasi diri baik untuk diri sendiri dan lainnya. Jika di dalam pemahaman diri ada penyimpangan dalam perilaku, psikologi Islam mencoba menawarkan berbagai konsep dengan nuansa ilahi, sehingga dapat mengarahkan kualitas hidup yang lebih baik, yang pada gilirannya dapat menikmati kebahagiaan hidup di segala usia. Dengan demikian, mempelajari psikologi Islam dapat memiliki implikasi untuk membuat diri Anda dan orang lain bahagia, tidak menambah masalah baru seperti hidup dalam kesendirian, kegersangan dan kecemasan.

Psikologi Islam umumnya, telah mendapat persetujuan dari umat Islam. Adapun, jika orang lain bisa mengusulkan pemikiran psikologis melalui pola pikir (pendapat) mereka sendiri, dan mengklaim validitas dan objektifitasnya, maka mengapa kita tidak melakukan hal yang sama, yakni mempromosikan pemikiran psikologi Islam, yang berdasarkan pola pemikiran Islam. ${ }^{7}$

\section{Pengertian Dosa}

Istilah dosa dalam Islam memiliki beberapa penamaan yang berbeda dan dosa (pada pengertian umum) tidak sesederhana definisi dosa itu sendiri, itu dapat dianggap sebagai dosa (nama tertentu) setelah seseorang melakukan tindakan dengan hukum-hukum yang melekat tertentu, demikian dalam pengampunan dalam dosa itu. Jadi dalam Islam ada beberapa nama yang bermakna "dosa", diantaranya; ; al- 
Itsm, adz-Dzanb, al-Khathiah, asy-Syar, al-Hints, adz-Dzanb, asSayyiah, al-Ma'shiyah, al-Jurm, al-haram, al-Fisq, al-fasad, alFujur, al-Munkar, al-Fahisyah, al-Khabt, al-Lamama, al-Wizr wats-tsiqal. Penamaan tersebut memiliki arti yang berbeda, hukum yang berbeda dan cara pengampunan yang berbeda. Dengan nama yang berbeda, menunjukkan banyak jenis perilaku manusia yang berbeda dari tindakan yang dilanggar. ${ }^{8}$

Menurut bahasa, itsm menurut bahasa adalah melakukan tindakan yang tidak dihalalkan ${ }^{9}$. Dzamb sesuatu yang mengikuti, segala perbuatan yang menyalahi aturan Allah dan RasulNya akan mendapatkan balasan di dunia dan akhirat ${ }^{10}$. Khatiah, bermakna kesalahan, yaitu sesuatu perbuatan yang menyalahi perintah Allah dan RasulNya, dan terkadang bermakna dosa besar ${ }^{11}$. Fisq, artinya keluarnya biji kurma dari kulitnya, orang yang melampaui batas hukumhukum Allah ${ }^{12}$, Ishyan, keluar dari ketaatan, menyalahi perintahnya. ${ }^{13}$

Istilah Alquran untuk kata dosa juga banyak digunakan seperti lafaz khati'ah, zanbun, ismun, fisq, isyan, 'utwun dan fasad dan kata-kata ini digunakan oleh Alquran untuk mengekspresikan sikap dan tindakan manusia yang melanggar

8 Halimi Zuhdy Derai Dosa, Derasnya Ampunan Sang Penguasa Semesta: Membincang Dosa dan Pengampunan dalam Perspektif Islam. Dosa dan Pengampunan: Pergulatan Manusia dengan Allah. (Widyasana, Malang, 2016). hs. 1-2

9 Muhammad bin Mukrim bin Ali Abu Fadl Ibnu Mandzur. Lisan Arab. (Dar Shadir. Bairut: 114 H). h. 74. Dalam Halimi Zuhdy Derai Dosa, Derasnya Ampunan Sang Penguasa Semesta. h. 2.

10 Ibnu Mandzur. h. 244. Dalam Halimi Zuhdy, Derai Dosa, Derasnya Ampunan Sang Penguasa Semesta. h. 2.

${ }^{11}$ As-Shihah. As-Shihah Fi Lughah. (t.tp: Dun Sanah, 1987). h. 47.

12 Halimi Zuhdy, Derai Dosa, Derasnya Ampunan Sang Penguasa Semesta. h. 2.

13 Ibnu Mandzur. h. 47. Dalam Halimi Zuhdy, Derai Dosa, Derasnya Ampunan Sang Penguasa Semesta, h. 2.

TAHDIS Volume 10 Nomor 2 Tahun 2019 
moral dan hukum Allah. Meskipun Alquran menyebutkan katakata ini dalam istilah yang berbeda, pada prinsipnya tidak ada perbedaan, umumnya maknanya hampir sama. ${ }^{14}$ Oleh karena itu dapat disimpulkan, bahwa dosa adalah tindakan yang melanggar perintah Allah dan Rasul-Nya, yang telah ditetapkan untuk ditaati, dan pelakunya akan diberikan sanksi (uqubat) baik ketika di dunia dan juga di akhirat.

\section{Hadis tentang Dosa Membuat Jiwa Gelisah}

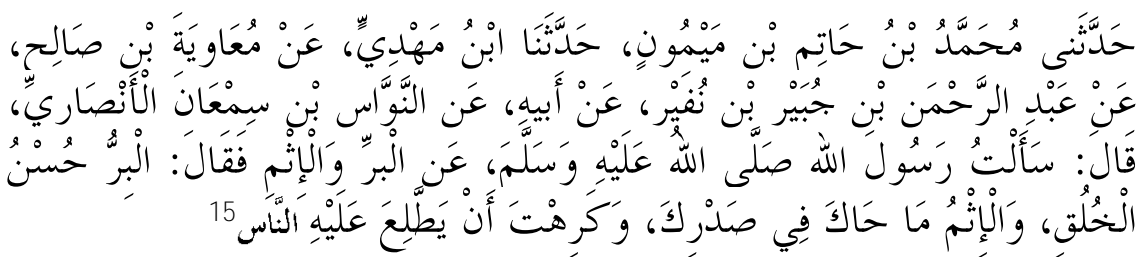

Artinya:

Menceritakan kepadaku Muhammad bin Hatim bin Maimun, menceritakan kepada kami Ibn Mahdi, dari Mu'awiyah bin Salih, dari 'Abd al-Rahman bin Jubair bin Nufair, dari bapaknya, dari al-Nawas bin Sim'an alAnsari berkata: saya bertanya kepada Rasulullah saw. tentang kebajikan dan dosa, maka beliau bersabda: kebaikan adalah akhlak yang mulia, sedangkan dosa adalah sesuatu yang menggelisahkan jiwa, dan dosa tersebut akan terlihat buruk ditengah-tengah manusia. (HR. Muslim)

\section{Syarah Mufradat}

1.

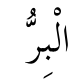

14 Yahya Jaya. Peran Dan Maaf dalam Kesehatan Mental. (YPI Ruhama. Jakarta, 1989), h. 30.

${ }_{15}$ Muslim bin al-Hajjaj Abu al-Hasan al-Qusyairi al-Naisaburi, Sahih Muslim, Juz IV (t.c; Beirut: Dar Ihya' al-Turas al-'Arabi, t.th), h. 1980.

TAHDIS Volume 10 Nomor 2 Tahun 2019 
Kata al-birr berasal dari akar kata barra - yabarru. ${ }^{16}$ Menurut Ibnu Faris, kata ini memiliki empat arti dasar, (1), benar dan jujur, (2) ihwal pembicaraan, cerita, (3) lawan kata dari lautan, dan (4) tumbuhan. ${ }^{17}$ Sementara itu, alAsfahani menyebutkan bahwa kata al-barr yang berarti daratan merupakan lawa kata dari al-bahr. al-bahr dalam konteks ini dimaknai dengan "keluasan" karena peluang untuk berbuat keburukan lebih besar dibandingkan kebajikan, atau al-birr. Selanjutnya, disebutkan bahwa apabila al-barr dilakukan kepada Allah maka berarti "pahala", sedangkan apabila dilakukan kepada manusia berarti "ketaatan". Oleh karena itu, al-Asfahani menyebutkan bahwa makna al-birr mencakup dua aspek. Pertama, pekerjaan hati dengan niat yang suci, dan kedua, pekerjaan anggota badan. ${ }^{18}$ Jadi, sesuatu disebut dengan al-birr apabila telah memenuhi dua aspek di atas.

2. רُنْن

Kata husn merupakan bentuk masdar dari kata hasuna ${ }^{19}$ yang berarti kebaikan, antonim dari kata al-qibh ${ }^{20}$ yang berarti keburukan. Menurut al-Asfahani, kata hasuna merupakan ungkapan terhadap hal yang indah yang disukai. Sesuatu yang dikatakan baik atau indah, ada tiga macam: sesuatu yang dianggap baik oleh akal, sesuatu yang

16M. Quraish Shihab, ed., Ensiklopedia al-Qur'an: Kajian Kosa Kata, Juz I (Cet. I; Jakarta Lentera Hati, 2007), h. 145

${ }^{17} \mathrm{Abu}$ al-Husain Ahmad bin Faris bin Zakariya, Mu'jam Maqayis alLugah, Juz I (t.c; t.tp: Dar al-Fikr, 1979 M/ 1399 H), h. 177.

${ }^{18} \mathrm{Abu}$ al-Qasim al-Husain bin Muhammad al-Ragib al-Asfahani, alMufradat fi Garib al-Qur'an, Juz I, h. 144.

${ }^{19}$ Ahmad Mukhtar 'Abdu al-Hamid 'Umar, Mu'jam al-Lugah al'Arabiyah al-Mu'asarh, Juz I (Cet. I; t.tp: 'A<lim al-Kutub, 2008M/ 1429 H), h. 498.

${ }^{20} \mathrm{Abu}$ al-Husain Ahmad bin Faris bin Zakariya, Mu'jam Maqayis alLugah, Juz II, h. 57.

TAHDIS Volume 10 Nomor 2 Tahun 2019 
dianggap baik oleh hawa nafsu dan sesuatu yang dianggap baik oleh panca indra. ${ }^{21}$

Kata husn sendiri secara umum bermakna sesuatu hal yang baik dan indah, baik yang nampak maupun yang tidak nampak, sehingga dapat membuat sesuatu dapat menerima, tertarik, dan berkeinginan atasnya. ${ }^{22}$ Terdapat perbedaan antara kata husn, hasanah dan husna. Kata husn dapat diucapkan pada benda dan juga suatu peristiwa. Begitu pula dengan kata hasanah, apabila kata ini diposisikan sebagai kata sifat. Sedangkan apabila diposisikan sebagai kata benda, maka kata ini hanya digunakan dalam peristiwa. Adapun kata husna, ia hanya dapat digunakan pada peristiwa, tidak bisa digunakan sebagai kata benda.

Kata husn, dikalangan masyarakat umum sering digunakan untuk sesuatu yang dianggap baik oleh mata lahir. Hal ini sebagaimana penggunaanya dalam Alquran yang kebanyakan digunakan untuk mengungkapkan sesuatu yang dianggap baik. ${ }^{23}$

\section{3.}

Kata itsm merupakan bentuk masdar dari akar kata atsima ya'tsamu yang berarti sesuatu yang terlambat atau tertunda. ${ }^{24}$ Perbuatan yang dapat menyebabkan ditundanya pahala disebut dengan itsm. Dalam perkembangannya, kata ini kemudian diartikan dengan dosa. Diartikan dengan dosa karena perbuatan-perbuatan

${ }^{21} \mathrm{Abu}$ al-Qasim al-Husain bin Muhammad al-Ragib al-Asfahani, alMufradat fi Garib al-Qur'an, Juz I, h. 235.

${ }^{22}$ Ahmad Mukhtar 'Abdu al-Hamid 'Umar, Mu'jam al-Lugah al'Arabiyah al-Mu'asarh, Juz I, h. 498.

${ }^{23} \mathrm{Abu}$ al-Qasim al-Husain bin Muhammad al-Ragib al-Asfahani, alMufradat fi Garib al-Qur'an, Juz I, h. 236.

${ }^{24} \mathrm{Abu}$ al-H\{usain Ah\{mad bin Faris bin Zakariya, Mu'jam Maqayis alLugah, Juz I, h. 60. 
yang buruk, yang dapat terhambatnya pahala, merupakan perbuatan yang tercela sehingga dapat menjerumuskan kepada dosa. ${ }^{25}$

4.<smiles>[AlH2]</smiles>

Kata sadr merupakan bentuk tunggal dari kata sudur yang terambil kata sadara - yasduru yang berarti bagian atas atau depan dari segala sesuatu. Apa yang ada dibagian depan manusia disebut dengan sadr, sehingga dada disebut demikian. Namun demikian, secara umun kata sadr tidak dimaknai dengan dada secara fisik. ${ }^{26}$ Hal ini sebagaimana penggunaannya dalam QS. Taha/20: 25.

Artinya:

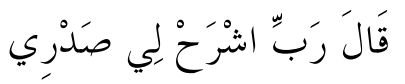

Berkata (Musa), "Ya Tuhanku, lapangkanlah untukku dadaku.

Dengan demikian, yang dimaksud dengan sadr dada-, bukanlah sesuatu yang berbentuk materi, tetapi sesuatu dibalik itu. Penggunaan redaksi seperti ini dikenal dalam bahasa Arab dengan istilah majaz mursal. ${ }^{27}$

\section{Syarah Hadits: Dosa Membuat Jiwa Gelisah}

Setiap manusia memiliki naluri untuk mengerjakan nilai-nilai yang positif. Jadi, pada dasarnya setiap manusia memiliki identitas kemuliaan. Oleh karena itu, apabila manusia melakukan perbuatan yang tidak berdasarkan nilai-nilai positif, maka manusia tersebut mengingkari identitasnya sendiri.

${ }^{25} \mathrm{Abu}$ al-Qasim al-Husain bin Muhammad al-Ragib al-Asfahani, alMufradat fi Garib al-Qur'an, Juz I, h. 63.

${ }^{26}$ M. Quraish Shihab, ed., Ensiklopedia al-Qur'an: Kajian Kosa Kata, Juz III, h. 907.

${ }^{27}$ M. Quraish Shihab, ed., Ensiklopedia al-Qur'an: Kajian Kosa Kata, Juz III, h. 907. 
Manusia yang tidak bertindak positif itulah yang akan membawa kepada kegelisahan jiwa karena mengingkari sifat naluriahnya. ${ }^{28}$

Di dalam agama Islam, perbuatan yang membawa kepada nilai-nilai negatif disebut dengan dosa. Dosa tersebutlah yang membuat jiwa seseorang menjadi gelisah. Nabi saw. bersabda:

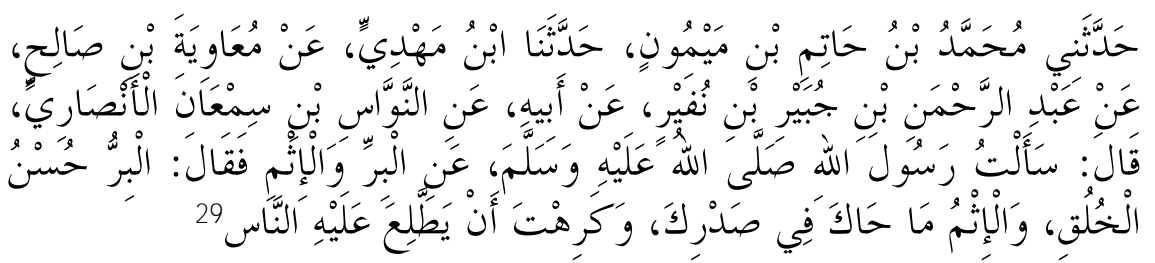

Artinya:

Menceritakan kepadaku Muhammad bin Hatim bin Maimun, menceritakan kepada kami Ibn Mahdi, dari Mu'awiyah bin Salih, dari 'Abd al-Rahman bin Jubair bin Nufair, dari bapaknya, dari al-Nawas bin Sim'an al-Ansari berkata: saya bertanya kepada Rasulullah saw. tentang kebajikan dan dosa, maka beliau bersabda: kebaikan adalah akhlak yang mulia, sedangkan dosa adalah sesuatu yang menggelisahkan jiwa, dan dosa tersebut akan terlihat buruk ditengah-tengah manusia. (HR. Muslim)

Sebelum membahas lebih lanjut, perlu diuraikan bahwa manusia pada dasarnya diberikan dua potensi, yaitu potensi akal dan hati. Manusia hendaknya menggunakan dua potensi tersebut secara seimbangan. Akal bertujuan untuk merenungkan, sedangkan hati bertujuan untuk membenarkan suatu tindakan. Apabila keduanya saling bertentangan dalam

${ }^{28}$ Muhammad Taqi Ja'fari, Mengenal Tasawuf Positif, terj. Ali Yahya (Cet. I; Jakarta: Nur al-Huda, 2011), h. 19.

${ }^{29}$ Muslim bin al-Hajjaj Abu al-Hasan al-Qusyairi al-Naisaburi, Sahih Muslim, Juz IV, h. 1980. 
suatu tindakan, maka hendaknya manusia tidak mengambil tindakan tersebut karena dapat mengakibatkan keburukan.

Namun jika keduanya bertentangan dan tetap harus mengambil suatu tindakan, maka hendaknya mengikuti potensi hati. Hal ini dikarenakan potensi hati dianggap sebagai sumber kebenaran yang hakiki yang oleh ajaran Islam, ia disebut dengan iman. Oleh sebab itu, apabila seseorang hendak terhindar dari dosa maka segala tindakannya harus berdasarkan pembenaran hati (iman). Orang yang tidak bertindak berdasarkan hatinya dikecam oleh Alquran, Allah swt. berfirman dalam QS. al-A'raf/7: 179.

Artinya:

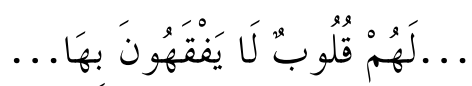

“..mereka mempunyai hati tetapi tidak dipergunakannya.."30

Dosa dapat dilakukan oleh seseorang karena disebabkan hilangnya pancaran iman dari dalam hatinya. Jika pancaran iman seseorang hilang dari dalam hatinya kemudian digantikan dengan kezaliman, maka kezaliman tersebut akan mengantarnya untuk melakukan kezaliman yang lain. Keadaan seperti ini juga digambarkan oleh hadis Nabi saw.

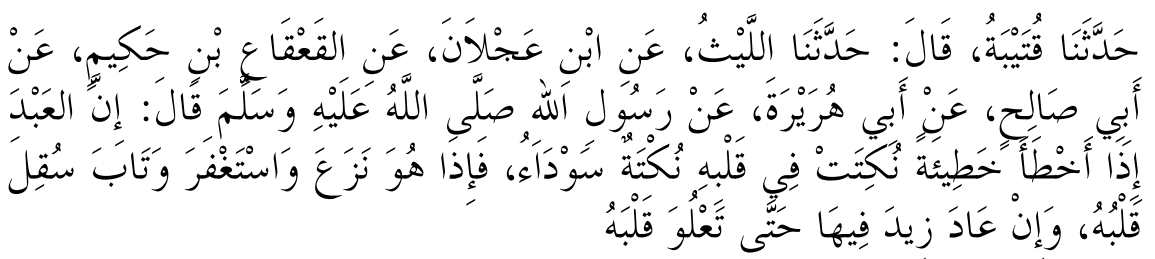

Artinya:

Menceritakan kepada kami Qutaibah, dia berkata: menceritakan kepada kami al-Lais, dari Ibn 'Ajlan, dari al-

${ }^{30}$ Kementerian Agama Republik Indonesia, Al-Mahir Al-Qur'an dan Terjemah Tajwid Warna, h. 174.

TAHDIS Volume 10 Nomor 2 Tahun 2019 
Qa'qa' bin Hakim, dari Abi Salih, dari Abu Hurairah, dari Rasulullah saw. bersabda: jika seorang hamba berbuat satu kesalahan maka pada hatinya akan tercatat satu titik hitam. Jika dia bertobat maka titik tersebut akan dihapus. Namun jika dia mengulanginya maka titik tersebut bertambah lagi hingga menutupi hatinya. (HR. Tirmizi)

Adapun Imam al-Nawawi menjelaskan bahwa yang menyebabkan sesorang gelisah terhadap dosanya, ialah karena dosa tersebut akan membuat seseorang terus menerus dalam keadaan takut dan ragu. Pada prinsipnya, kegelisahan terjadi pada seseorang yang berbuat dosa, karena sebenarnya seseorang tersebut mengetahui bahwa perbuatannya tersebut salah. Pengetahuan tersebut diperoleh dari nalurinya sendiri. Namun, ia tetap mengingkari nalurinya. ${ }^{31}$

Allah swt. Berfirman:

Artinya:

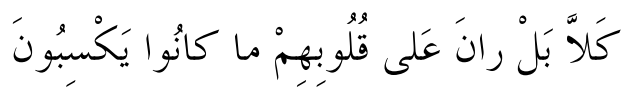

Sekali-kali tidak (demikian), sebenarnya apa yang selalu mereka usahakan itu menutupi hati mereka. (QS. alMutaffifin/83: 14)

Adapun agar tidak terjerumus dalam keadaan takut dan ragu yang disebabkan karena dosa, perlu adanya pencegahan dan penghindaran. Salah satu solusi yang ditawarkan oleh hadis demi pencegahan tersebut ialah meninggalkan sesuatu yang meragukan.

${ }^{31}$ Nasr al-Din Abu Sa'id 'Abdullah bin 'Umar al-Baidawi, Anwar alTanzil wa Asrar al-Ta'wil, Juz V (Cet. I; Beirut: Dar Ihya' al-Turas al-'Arabi, 1418), h. 295. 


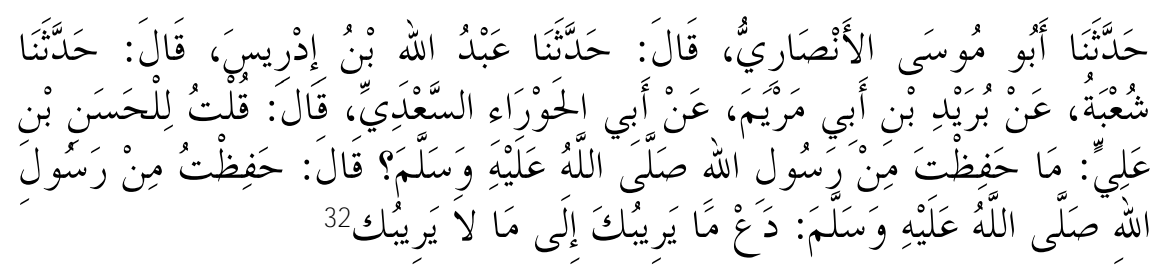

Artinya:

Menceritakan kepada kami Abu Musa al-Ansari, dia berkata: menceritakan kepada kami 'Abdullah bin Idris, dia berkata: menceritakan kepada kami Syu'bah, dari Buraid bin Abi Maryam, dari Abi al-Hawra', dia berkata: Aku berkata kepada Hasan: Apa yang kamu hafal dari Rasulullah saw.?, dia (Hasan) berkata: Saya telah menghafal dari Rasulullah saw: Tinggalkanlah apa yang meragukan bagimu kepada apa yang tidak meragukan bagimu. (HR. al-Tirmizi)

\section{Dampak Dosa Terhadap Kepribadian Seseorang}

Kegelisahan jiwa seseorang sangat berkaitan dengan emosional. Menurut James dan Lange, emosi itu timbul karena pengaruh perubahan jasmani atau pengaruh kegiatan individu seseorang. Oleh karena itu, jika seseorang bertindak kepada sesuatu yang benar maka akan membawa kepada emosi yang positif sehingga tercipta ketenangan jiwa. Begitupun sebaliknya, jika seseorang bertindak kepada sesuatu yang buruk, maka akan membawa kepada emosi negatif sehingga tercipta kegelisahan jiwa. ${ }^{33}$ Adapun menurut John B. Waston, bahwa tiga pola dasar emosi ialah takut (fear), marah (anger), dan cinta (love). Pola takut dan marah bisa timbul karena

${ }^{32}$ Muhammad bin 'Isa bin Saurah bin Musa bin al-Dahak al-Tirmuzi, al-Jami' al-Kabir, Juz IV, h. 249.

${ }^{33}$ https://www.verywellmind.com/what-is-the-james-langetheory-of-emotion-2795305, diakses pada 21 November 2019. 
pengaruh stimulus negatif, sedangkan cinta dipengaruhi oleh stimulus positif. ${ }^{34}$

Teori-teori yang dikemukakan oleh pakar psikologi di atas, sejalan dengan apa yang dikemukakan oleh dalil-dalil teologis. Jika sesorang berbuat kebaikan (sesuatu yang berpahala), maka akan membawa kepada ketenangan jiwa, akibat rahmat yang dicurahkan kepadanya. Begitupun sebaliknya, jika seseorang berbuat keburukan (dosa), maka ketenangan jiwanya akan terganggu akibat murka Allah swt. yang diberikan kepadanya.

Menurut Abu Abdillah Muhammad (1997) dalam kitab al-jawab al-kafi liman saala an dawa kafi, dosa-dosa itu akan mengakibatkan; Maksiat merupakan sebab dihinakannya seorang hamba oleh Rabbnya. Bila seorang hamba terus menerus berbuat dosa, pada akhirnya ia akan meremehkan dosa tersebut dan menganggapnya kecil. Ini merupakan tanda kebinasaan seorang hamba, perbuatan dosanya akan berakibat pada orang lain, dan sekitarnya, bila dosa telah menumpuk, hati pun akan tertutup dan mati, dosa akan merusak akal, karena akal adalah cahaya, dan dosa akan memadamkan cahaya, hilangnya rasa malu, yang merupakan kebaikan, menghilangkan kenikmatan, dan akan selalu merasakan kesengsaraan, tertutupnya seseorang dari mendapatkan ilmu yang benar, ketakutan yang luar biasa, keresahan hati, tidak menemukan keindahan hidup, dan merasa malu ketika dosanya dilihat oleh orang lain. ${ }^{35}$

34Yudrik Jahja, Psikologi Perkembangan, h. 191.

35 Abu Abdullah bin Abi Bakr Muhammad, Al-Jawab al-Kafi liman saala an al-dawa' alsyafi. (t.tp: Darul Ma'rifah, 1997). h. 124-192. 


\section{Penutup}

Setiap manusia memiliki naluri untuk mengerjakan nilai-nilai yang positif. Jadi, pada dasarnya setiap manusia memiliki identitas kemuliaan yang telah sesuai yang diajarkan dalam Alquran dan Hadis. Oleh karena itu, apabila manusia melakukan perbuatan yang tidak berdasarkan nilai-nilai positif, maka manusia tersebut mengingkari identitasnya sendiri (fitrah). Manusia yang tidak bertindak positif (melakukan dosa) itulah yang akan membawa kepada kegelisahan jiwa karena mengingkari sifat naluriahnya. Imam al-Nawawi menjelaskan bahwa yang menyebabkan sesorang gelisah terhadap dosanya, ialah karena dosa tersebut akan membuat seseorang terus menerus dalam keadaan takut dan ragu. Pada prinsipnya, kegelisahan terjadi pada seseorang yang berbuat dosa, karena sebenarnya seseorang tersebut mengetahui bahwa perbuatannya tersebut salah. Pengetahuan tersebut diperoleh dari nalurinya sendiri. Namun, ia tetap mengingkari nalurinya. Adapun agar tidak terjerumus dalam keadaan takut dan ragu yang disebabkan karena dosa, perlu adanya pencegahan dan penghindaran. Salah satu solusi yang ditawarkan oleh hadis demi pencegahan tersebut ialah meninggalkan sesuatu yang meragukan. 


\section{DAFTAR PUSTAKA}

Alquran al-Karim

al-Asfahani, Abu al-Qasim al-Husain bin Muhammad al-Ragib. al-Mufradat fi Garib Alquran. Cet. I; Beirut: Dar al-Qalam, $1412 \mathrm{H}$.

al-Baidawi, Nasr al-Din Abu Sa'id 'Abdullah bin 'Umar. Anwar al-Tanzil wa Asrar al-Ta'wil. Cet. I; Beirut: Dar Ihya' alTuras al-'Arabi, 1418.

Ibnu Mandzur, Muhammad bin Mukrim bin Ali Abu Fadl (1414 H). Lisan Arab. Dar Shadir. Bairut.

Jaya, Yahya. Peran Dan Maaf dalam Kesehatan Mental. (YPI Ruhama. Jakarta, 1989.

Ja'fari, Muhammad Taqi. Mengenal Tasawuf Positif. Terj. Ali Yahya. Cet. I; Jakarta: Nur al-Huda, 2011.

Jahja, Yudrik. Psikologi Perkembangan. Cet. II; Jakarta: Kencana, 2012.

Kementerian Agama Republik Indonesia. Al-Mahir Alquran dan Terjemah Tajwid Warna. t.c; Sukoharjo: Penerbit Madina Qur'an, 2016.

al-Maturidi, Muhammad bin Muhammad bin Mahmud Abu Mansur. Ta'wilat Ahl Sunnah. Cet. I; Beirut: Dar al-Kutub al-'Ilmiyah, $2005 \mathrm{M} / 1426 \mathrm{H}$.

Muhammad, Abu Abdullah bin Abi Bakr, Al-Jawab al-Kafi liman saala an al-dawa' alsyafi. t.tp: Darul Ma'rifah, 1997.

Muslim, al-Hajjaj Abu al-Hasan al-Qusyairi al-Naisaburi. Sahih Muslim. t.c; Beirut: Dar Ihya' al-Turas al-'Arabi, t.th.

Nata, Abuddin. Psikologi Pendidikan Islam. Cet. I; Depok: Rajagrafindo Persada, 2018.

al-Nawawi Abu Zakariya Mahyu al-Din Yahya . al-Manhaj Syarh Sahih Muslim bin al-Hajjaj. Cet. II; Beirut: Dar Ihya' alTuras al-'Arabi, $1392 \mathrm{H}$. 
al-Qurtubi, Abu 'Abdillah Muhammad Syamsu al-Din. Tafsir alQurtubi. Cet. II; Kairo: Dar al-Kutub al-Misriyah, 1964 $\mathrm{M} / 1384 \mathrm{H}$.

Rahmi, Novita, "Manusia dalam Perspektif Psikologi Pendidikan Islam", Dewantara 11. 2016.

Shihab, M. Quraish, ed.. Ensiklopedia Alquran: Kajian Kosa Kata.

Cet. I; Jakarta Lentera Hati, 2007.

As-Shihah. As-Shihah Fi Lughah. t.tp: Dun Sanah, 1987.

al-Tirmuzi, Muhammad bin 'Isa bin Saurah bin Musa bin alDahak. al-Jami' al-Kabir. t.c; Beirut: Dar al-Garb al-Islami, $1998 \mathrm{M}$.

'Umar, Ahmad Mukhtar 'Abdu al-Hamid. Mu'jam al-Lugah al'Arabiyah al-Mu'asarh. Cet. I; t.tp: 'A<lim al-Kutub, 2008M/ $1429 \mathrm{H}$.

Zakariya, Abu al-H\{usain Ah\{mad bin Faris. Mu'jam Maqayis alLugah. t.c; t.tp: Dar al-Fikr, 1979 M/ 1399 H.

Zuhdy, Halimi. Derai Dosa, Derasnya Ampunan Sang Penguasa Semesta: Membincang Dosa dan Pengampunan dalam Perspektif Islam. Dosa dan Pengampunan: Pergulatan Manusia dengan Allah. Malang: Widyasana, 2016.

Website

Fitriana, "Pengertian, Dasar dan Ruang Lingkup Psikologi Islam", diakses pada: 21-November-2019.

- $\quad$ https://www.verywellmind.com/what-is-the-jameslange-theory-of-emotion-2795305, diakses pada 21 November 2019. 